\title{
Design and Synthesis of Lactose, Galactose and Cholic Acid Related Dual Conjugated Chitosan Derivatives as Potential Anti Liver Cancer Drug Carriers
}

\author{
Yili Ding ${ }^{1, *}$, Wutong Cui ${ }^{1}$, Chamakura V. N. S. Vara Prasad ${ }^{2}$ and Bingyun Wang ${ }^{1}$ \\ 1 Life Science Department, Foshan University, Foshan 528000, China; linlincui123456@163.com (W.C.); \\ bywang63@163.com (B.W.) \\ 2 Das Pharma, Turangi P.O., Kakinada 533016, India; vchamakura@gmail.com \\ * Correspondence: Yiding93@yahoo.com; Tel.: +86-140-8549-6168
}

Citation: Ding, Y.; Cui, W.; Vara

Prasad, C.V.N.S.; Wang, B. Design and Synthesis of Lactose, Galactose and Cholic Acid Related Dual Conjugated Chitosan Derivatives as Potential Anti Liver Cancer Drug Carriers. Polymers 2021, 13, 2939. https://doi.org/10.3390/polym13172939

Academic Editor: Alejandro Sosnik

Received: 29 July 2021

Accepted: 25 August 2021

Published: 31 August 2021

Publisher's Note: MDPI stays neutral with regard to jurisdictional claims in published maps and institutional affiliations.

Copyright: (c) 2021 by the authors. Licensee MDPI, Basel, Switzerland. This article is an open access article distributed under the terms and conditions of the Creative Commons Attribution (CC BY) license (https:// creativecommons.org/licenses/by/ $4.0 /)$.

\begin{abstract}
Cholic acid and galactose or lactose dual conjugated chitosan derivatives were designed and synthesized as potential anti liver cancer drug carriers, their structures were characterized through proton NMR spectra, elemental analysis, size distribution, zeta potential, and scanning electron microscope image studies. The ability of the dual conjugates to enhance the aqueous solubility of the cancer drug sorafenib was evaluated. The entrapment efficiency (EE\%) and drug content (DC\%) of sorafenib in the inclusion complexes were measured. The chitosan dual conjugate with cholic acid and galactose was found to be best in enhancing the aqueous solubility of sorafenib. The solubility of sorafenib in water has increased from $1.7 \mu \mathrm{g} / \mathrm{mL}$ to $1900 \mu \mathrm{g} / \mathrm{mL}$ which is equal to 1117 -fold increase in its solubility due to the inclusion complex with chitosan conjugate.
\end{abstract}

Keywords: lactose; galactose; cholic acid; dual conjugated chitosan derivatives; sorafenib; solubility

\section{Introduction}

Many of the existing cancer drugs with low water-solubility, non-specific targeting of cancer cells, and lower stability face a barrier for the drugs to reach the tumor area with maximum efficacy. The design and synthesis of the drug carriers with the cancer-specific tumor biomarkers and other functional groups to increase cancer drug's tumor-targeting ability, absorptive transportation, in vivo stability, and systemic solubility, while reducing the adverse effects, is a potential therapeutic approach to treat cancer diseases with the high efficacy.

It was shown that the conjugation of carriers with antibodies and their variable fragments, peptides, nucleic aptamers, vitamins, and carbohydrates can lead the drug delivery to cancer cells [1]. The targeted drug delivery system is comprised of three components: a therapeutic agent, a targeting moiety, and a carrier system [2].

Chitosan, a natural polysaccharide [3], has received increasing attention due to its outstanding physical and biological properties such as biocompatibility, biodegradability, nontoxicity, low-immunogenicity, abundant availability, unique mucoadhesivity, and inherent pharmacological properties [4-6]. The chemical modification of chitosan through conjugating with hydrophobic moiety imparts amphiphilicity, which enables it in the formation of self-assembled nanoparticles [7], and the resulting hydrophobic cores of nanoparticles could act as reservoirs or microcontainers for various bioactive substances. Cholic acid, an endogenous amphiphilic steroid, is used as the shuttle to deliver drugs precisely to the liver [8-15]. The cholic acid conjugated chitosan nanoparticles were demonstrated as the drug carriers for paclitaxel. The paclitaxel-loaded nanoparticles showed remarkably high anticancer activity compared to that of paclitaxel in Cremophor EL-ethanol formulation against B16F10 cells [16]. Carbohydrate-bearing chitosans were also found to be promising liver-targeted [17,18] nanocarriers for hepatic drug targeted delivery [19-22]. 
Thus, the ability of mono-conjugated chitosan derivatives, such as cholic acid conjugated chitosan, lactose linked chitosan, and galactose conjugated chitosan as drug carriers to deliver the anticancer agents to the liver has been known for some time. As part of our interest in employing biomolecules as drug carriers for dual targeting [23] of liver cancer cells, we anticipate that the bifunctionalized chitosan compounds can also be employed as drug carriers for targeting liver cancer cells, and these chitosan-linked molecules may increase the drug's targeting efficacy, apart from improving drug's water solubility and stability in comparison with monofunctionalized chitosan conjugates. In this communication, we report preliminary results on the design and synthesis of dual functionalized chitosan derivatives, and their evaluation in increasing the liver cancer drug's water solubility. The proposed galactose or lactose and cholic acid dual-linked chitosan compounds may act as the polysaccharide nanosized drug carriers, and their structures $(\mathbf{1}, \mathbf{2}$ and $\mathbf{3})$ are listed in Figure 1.

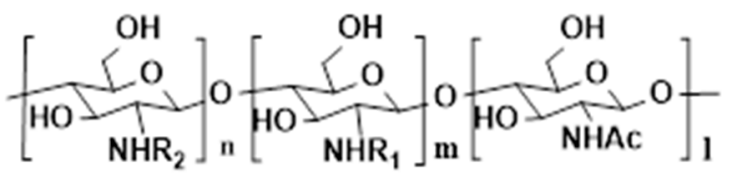

Chitosan: $\mathrm{R}_{1}=\mathrm{R}_{2}=\mathrm{H}$

1. $\mathrm{R}_{1}=$ Cholic acid or $\mathrm{H} ; \mathrm{R}_{2}=$ Cholic acid or $\mathrm{H}$

2. $\mathrm{R}_{1}=\mathrm{COC}_{2} \mathrm{H}_{4} \mathrm{SGAor} \mathrm{H} ; \mathrm{R}_{2}=$ Cholic acid or $\mathrm{H}$

3. $\mathrm{R}_{1}=\mathrm{COC}_{2} \mathrm{H}_{4}$ SLA or $\mathrm{H} ; \mathrm{R}_{2}=$ Cholic acid or $\mathrm{H}$

SGA: Sulfur-linked galactoside

SLA: Sulfur-linked lactoside

Figure 1. The structures of designed compounds 1, 2 and 3.

Sorafenib is an orally administered multi-kinase inhibitor that prevents tumor growth by anti-angiogenic, anti-proliferative, and/or pro-apoptotic effects [24], and is practically insoluble in water $(1.7 \mu \mathrm{g} / \mathrm{mL})$ [25]. Currently, sorafenib is one of the earliest approved drugs in the market for treating liver cancer. However, its non-specific uptake may lead to serious adverse events such as the development of second primary cancer, difficulty breathing, pleural effusion [26], and may result in less efficacy [27]. A commonly used technique to increase the water solubility of drugs is by supramolecular complexation [28]. The results of employing the above chitosan conjugates 1, 2, and 3 as the dual liver cell targeting nano-drug carriers, to increase the water solubility of sorafenib [29], will be described as part of a demonstration of the usefulness of the described chitosan conjugates.

\section{The Experiments}

\subsection{Materials and Instruments}

Chitosan oligosaccharide ( $25 \mathrm{KDa}, 90 \%$ deacetylated products), cholic acid, 3-dicyclohexyl carbodiimide (DCC), $\mathrm{N}$-hydroxy succinimide (NHS), lactose, galactose, and sorafenib were purchased from Sigma. Other solvents and chemicals were used in the reagent grade. ${ }^{1} \mathrm{H}$ NMR spectra were recorded by Bruker spectrometer operating at $400 \mathrm{MHz}$ using $\mathrm{D}_{2} \mathrm{O}$ as lock solvent, and the sample concentration was maintained at $1.0 \mathrm{mg} / \mathrm{mL}$. The elemental analysis was carried out in Elementar (Langenselbold, Hesse Germany, Vario EL cube) instrument and the scanning electron microscope images were recorded on a Microsurface morphology (Hitachi, Tokyo, Japan). The dynamic light scattering experiment was carried out on an electrophoretic LS spectrophotometer (ELS-8000) and the UV spectra were obtained using a Lambda 25 UV-Vis spectrophotometer (PerkinElmer, Waltham, MA, USA).

\subsection{Experimental Procedures}

$\mathrm{N}$-Hydroxysuccinimidoyl cholic ester [17] (4): A mixture of cholic acid (0.32 g, $0.8 \mathrm{mmol})$, 3-dicyclohexyl carbodiimide (DCC) $(0.175 \mathrm{~g}, 0.8 \mathrm{mmol})$, and $\mathrm{N}$-hydroxy suc- 
cinimide (NHS) $(0.095 \mathrm{~g}, 0.8 \mathrm{mmol})$ in THF $(5 \mathrm{~mL})$ was stirred at room temperature for $24 \mathrm{~h}$ under nitrogen in the presence of DIEA $(0.1 \mathrm{~mL})$. The precipitated product dicyclohexylurea (DCU) was filtered off, and the solution of NHS ester 4 was used directly for the next reaction.

$N$-Hydroxysuccinimidoyl 3-( $\beta$-D-galactopyranosylthio)-propionate (6): A mixture of 3-( $\beta$-D-galactopyranosylthio)-propionic acid [30] (5) (0.22 g, $0.8 \mathrm{mmol}), 3$-dicyclohexyl carbodiimide (DCC) $(0.175 \mathrm{~g}, 0.8 \mathrm{mmol})$, and N-hydroxy succinimide (NHS) $(0.095 \mathrm{~g}$, $0.8 \mathrm{mmol})$ in THF/DMF $(1: 1,5 \mathrm{~mL})$ was stirred at room temperature for $24 \mathrm{~h}$ under nitrogen in the presence of DIEA $(0.1 \mathrm{~mL})$. The precipitated product dicyclohexylurea (DCU) was filtered off, and the solution of NHS ester 6 was used directly for the next reaction.

$N$-Hydroxysuccinimidoyl 3-( $\beta$-D-lactopyranosylthio)-propionate (8): A mixture of 3-( $\beta$-D-lactopyranosylthio)-propionic acid (7) [31] (0.34 g, $0.8 \mathrm{mmol}), 3$-dicyclohexyl carbodiimide (DCC) $(0.175 \mathrm{~g}, 0.8 \mathrm{mmol})$, and $\mathrm{N}$-hydroxy succinimide (NHS) $(0.095 \mathrm{~g}, 0.8 \mathrm{mmol})$ in THF/DMF $(1: 1,5 \mathrm{~mL})$ was stirred at room temperature for $24 \mathrm{~h}$ under nitrogen in the presence of DIEA $(0.1 \mathrm{~mL})$. The precipitated product dicyclohexylurea (DCU) was filtered off, and the solution of NHS ester 8 was used directly for the next reaction.

Cholic acid conjugated chitosan (1): To the solution of chitosan $(0.1 \mathrm{~g})$ in a mixture of DMSO $/ \mathrm{H}_{2} \mathrm{O}(10: 1,10 \mathrm{~mL})$ was added compound 4 obtained from $0.2 \mathrm{~g}$ of cholic acid in THF. The reaction mixture was stirred for $48 \mathrm{~h}$ at room temperature. Then, the resulting solution was precipitated by adding an excess amount of acetone/methanol (2:1). The precipitates were recovered by centrifugation and dried under a vacuum after washing out with acetone. The solid was dissolved into distilled water, and the solution was dialyzed against deionized water in $3000 \mathrm{Da}$ dialysis bags for $72 \mathrm{~h}$. The resulting solution was filtered through the $1.2 \mu \mathrm{m}$ pore sized syringe filter to remove large aggregates. Finally, the cholic acid conjugated chitosan (1) was obtained by lyophilization as a solid. Elemental analysis: C, 39.15\%; N, 6.03\%.

Cholic acid and 3-( $\beta$-D-galactopyranosylthio)-propionic acid conjugated chitosan (2): To the solution of chitosan $(0.1 \mathrm{~g})$ in a mixture of DMSO $/ \mathrm{H}_{2} \mathrm{O}(10: 1,10 \mathrm{~mL})$ was added compound 4 (obtained from $0.2 \mathrm{~g}$ of cholic acid) and compound 6 obtained from $0.15 \mathrm{~g}$ of 3-( $\beta$-D-galactopyranosylthio)-propionic acid (5) in THF. The reaction mixture was stirred for $48 \mathrm{~h}$ at room temperature under nitrogen. The resulting solution was precipitated by adding an excess amount of acetone/methanol (2:1). The precipitate was recovered by centrifugation and dried under a vacuum after washing out with acetone. The solid was dissolved into distilled water, and the solution was dialyzed against deionized water in $3000 \mathrm{Da}$ dialysis bags for $72 \mathrm{~h}$. The resulting solution was filtered through the $1.2 \mu \mathrm{m}$ pore-sized syringe filter to remove large aggregates. Finally, the cholic acid and 3-( $\beta$-D-galactopyranosylthio)-propionic acid conjugated chitosan (2) was obtained by lyophilization as a white solid. Elemental analysis: $C, 38.05 \%$; N $5.67 \% ; S, 3.42 \%$.

Cholic acid and 3-( $\beta$-D-lactopyranosylthio)-propionic acid conjugated chitosan (3): To the solution of chitosan $(0.1 \mathrm{~g})$ in a mixture of DMSO $/ \mathrm{H}_{2} \mathrm{O}(10: 1,10 \mathrm{~mL})$ was added compound 4 (obtained from $0.2 \mathrm{~g}$ of cholic acid) and compound 8 obtained from $0.3 \mathrm{~g}$ of 3-( $\beta$-D-lactopyranosylthio)-propionic acid (7) in THF. The reaction mixture was stirred for $48 \mathrm{~h}$ at room temperature, then the resulting solution was precipitated by adding an excess amount of acetone/methanol (2:1). The precipitate was recovered by centrifugation and dried under a vacuum after washing out with acetone. After dissolving in distilled water, the solution was then dialyzed against deionized water in $3000 \mathrm{Da}$ dialysis bags for $72 \mathrm{~h}$. After dialysis, the resulting solution was filtered through the $1.2 \mu \mathrm{m}$ pore-sized syringe filter to remove large aggregates. Finally, the cholic acid and 3-( $\beta$-D-lactopyranosylthio)propionic acid conjugated chitosan (3) was obtained by lyophilization as a white solid. Elemental analysis: C, 38.29\%; N, 6.23\%; S, 1.66\%.

Substitution degrees: The substitution degree of cholic acid DS in conjugate 1, substitution degrees of cholic acid (DS) and galactosyl part (DSgal) in conjugate 2, and substitution degrees of cholic acid (DS) and lactosyl part (DSlac) in conjugate 3 were obtained based on their elemental analysis data and following methods: 
For cholic acid conjugated chitosan derivative 1, since the starting material chitosan contains $10 \%$ of $N$-acetyl derivatives, every acetyl group contains two carbon atoms, every monosaccharide contains one nitrogen atom and six carbon atoms, and each cholic acid fragment contains 24 carbon atoms. Then, for every 100 monosaccharides, the ratio of C/N should be:

$$
C / N=[(100 \times 6 \times 12)+(10 \times 2 \times 12)+(24 \times 12 \times D S)] /(100 \times 1 \times 14)
$$

Based on the ratio of $\mathrm{C} / \mathrm{N}$ from elemental analysis, we can obtain the degree of substitution of cholic acid DS in conjugate $\mathbf{1}$.

For galactose and cholic acid conjugated chitosan derivative $\mathbf{2}$, every monosaccharide contains one nitrogen atom, each galactosyl fragment contains one sulfur atom, for every 100 monosaccharides, the ratio of $\mathrm{S} / \mathrm{N}$ should be:

$$
\mathrm{S} / \mathrm{N}=\left(1 \times 32 \times \mathrm{DS}_{\mathrm{gal}}\right) /(100 \times 1 \times 14)
$$

Based on the ratio of $\mathrm{S} / \mathrm{N}$ from elemental analysis, we are able to know the degree of substitution of galactosyl fragment $\left(\mathrm{DS}_{\mathrm{gal}}\right)$ in conjugate 2. Each cholic acid fragment contains 24 atoms, each galactosyl fragment contains nine carbon atoms, for every 100 monosaccharides, the ratio of $\mathrm{C} / \mathrm{N}$ should be:

$$
\mathrm{C} / \mathrm{N}=[(100 \times 6 \times 12)+(10 \times 2 \times 12)+(9 \times 12 \times \mathrm{DSgal})+(24 \times 12 \times \mathrm{DS})] /(100 \times 1 \times 14)
$$

Based on the ratio of $\mathrm{C} / \mathrm{N}$ from the elemental analysis, we are able to find the degree of substitution of cholic acid (DS) in conjugate 2 .

By using a similar method, we can find the degrees of substitution of lactosyl fragment and cholic acid in conjugate 3 .

Preparation of self-aggregated nanoparticles and the size distribution of nanoparticles and zeta potential determination: Chitosan conjugate 1, 2 or $\mathbf{3}$ was dispersed in water $(1.0 \mathrm{mg} / \mathrm{mL})$, and the mixture was shaken gently at room temperature for $48 \mathrm{~h}$. After three times sonication ( $2 \mathrm{~min}$ for each time at $80 \mathrm{~W}$ ), the solution was filtered through a filter $(1.2 \mu \mathrm{m})$ to remove any particulate matter. The size distribution of nanoparticles and zeta potential was determined by dynamic light scattering (DLS). The DLS experiment was carried out using an electrophoretic LS spectrophotometer (ELS-8000) equipped with a He-Ne laser operating at $632.8 \mathrm{~nm}$ at $25^{\circ} \mathrm{C}$ and a fixed scattering angle of $90^{\circ}$.

Scanning electron microscope images of chitosan conjugates: To observe the morphology of self-aggregated nanoparticles of chitosan conjugates 1, 2 and 3, the sample solutions $(1 \mathrm{mg} / \mathrm{mL})$ were dropped onto the carbon-coated 300 mesh copper grids. Then, the grids were air-dried and imaged using a scanning electron microscope (HITACHI, Tokyo, Japan) at an accelerating voltage of $80 \mathrm{kV}$.

Preparation of sorafenib loaded nanoparticles with chitosan conjugates 1, 2 and 3: The solution of sorafenib $(5 \mathrm{mg})$ in methanol $(1 \mathrm{~mL})$ was added into the solution of chitosan conjugate 1, 2 or $3(10 \mathrm{mg})$ in water $(10 \mathrm{~mL})$ slowly with stirring at room temperature. After ultrasound $(80 \mathrm{~W})$ for $30 \mathrm{~min}$, the mixture was put into water $(200 \mathrm{~mL})$ for dialysis for $24 \mathrm{~h}$. The solution was then centrifuged for $20 \mathrm{~min}$ at the rate of 10,000-12,000 rpm, and the resulting supernatant aqueous solution was lyophilized to give the sorafenib complexes as S1 (10.5 mg), S2 (12.3 mg), and S3 (11.8 mg).

Determination of drug content and encapsulating efficiency of sorafenib-loaded nanoparticles: The solution of sorafenib in acetonitrile was measured for its UV absorbance, and its maximum absorption is at $251 \mathrm{~nm}$. It is interesting to note that the chitosan conjugates 1, 2 and 3 have no UV absorption at $251 \mathrm{~nm}$. Based on the UV absorption of sorafenib in acetonitrile at $251 \mathrm{~nm}$ at different concentrations, a linear regression equation between the amount of sorafenib and UV absorption was obtained as $Y=1.6682 X+0.0451$, where the $\mathrm{Y}$ represented the amount of sorafenib, and the $\mathrm{X}$ represented the UV absorbance. The sorafenib-loaded nanoparticles $(5 \mathrm{mg}$ ) were dissolved in distilled water in $2 \mathrm{~mL}$, sonicated 
for $1 \mathrm{~min}$ (using a probe-type sonicator at $80 \mathrm{~W}$ ), and the UV absorbance of the resulting solution was measured; $1.6 \mathrm{mg}$ was found in sample $\mathbf{S 1}, 1.9 \mathrm{mg}$ was found in sample S2, and $1.7 \mathrm{mg}$ was found in sample S3. Based on these data, the drug contents (DC\%) and encapsulating efficiency (EE\%) were calculated by using the following formulas:

$$
\begin{gathered}
\mathrm{DC} \%=(\text { weight of the drug in complex/weight of feeding polymer and drug }) \times 100 \% \\
\mathrm{EE} \%=\text { (weight of the drug in complex/weight of the feeding drug }) \times 100 \%
\end{gathered}
$$

\section{Results and Discussion}

The amino groups in chitosan were linked to cholic acid, galactose and lactose related acid derivatives $(4,6$ and 8 ) through amide bond formation to generate compounds 1,2 and 3 respectively. Galactose and lactose related acid derivatives 5 and 7 were prepared by using the literature-reported procedures $[30,31]$. Thereafter, cholic acid, compounds 5 and 7 were activated by reaction with DCC and NHS in dry THF or DMF/THF to convert the carboxylic acid groups to NHS ester compounds 4, 6 and 8 (Scheme 1) respectively.
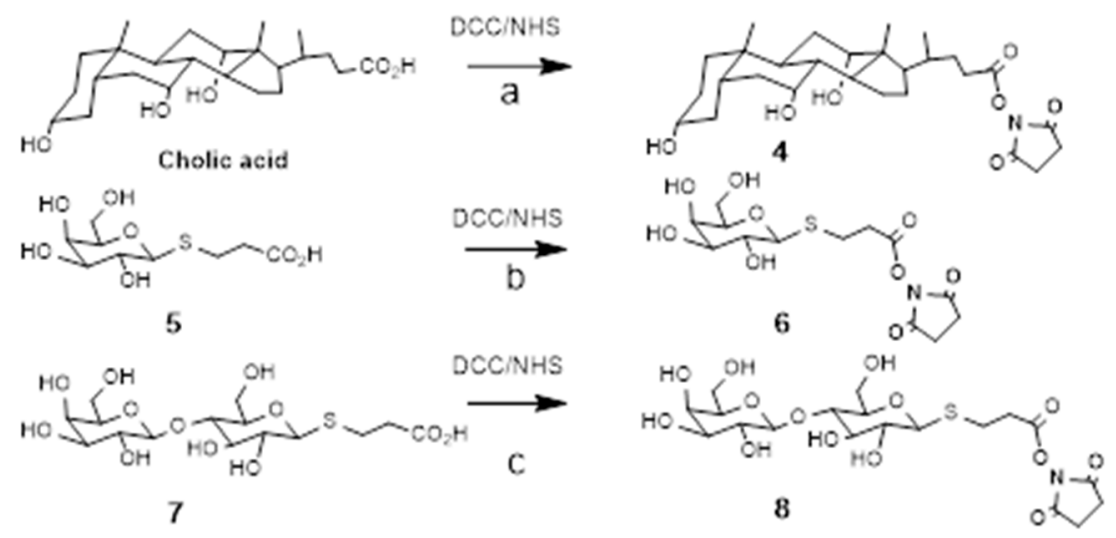

Scheme 1. Reagents and conditions. (a): cholic acid ( $0.8 \mathrm{mmol})$, DCC (0.8 mmol), NHS (0.8 mmol), dry THF ( $5 \mathrm{~mL})$, DIEA $(0.1 \mathrm{~mL})$, room temperature, $\mathrm{N}_{2}, 24 \mathrm{~h}$; (b): compound $5(0.8 \mathrm{mmol})$, DCC $(0.8 \mathrm{mmol})$, NHS ( $0.8 \mathrm{mmol})$, dry THF/DMF $(4: 1,5 \mathrm{~mL})$, DIEA $(0.1 \mathrm{~mL})$, room temperature, $\mathrm{N}_{2}, 24 \mathrm{~h}$; (c): compound 7 (0.8 mmol), DCC (0.8 mmol), NHS ( $0.8 \mathrm{mmol})$, dry THF/DMF $(4: 1,5 \mathrm{~mL})$, DIEA (0.1 mL), room temperature, $\mathrm{N}_{2}, 24 \mathrm{~h}$.

The NHS esters $\mathbf{4 , 6}$ and 8 were then reacted with chitosan in DMSO for $48 \mathrm{~h}$ and subjected to dialysis in water for $48 \mathrm{~h}$. Upon lyophilization of the resulting solutions, the cholic acid conjugated chitosan derivative $\mathbf{1}$, cholic acid and galactose conjugated chitosan derivative 2, cholic acid and lactose conjugated chitosan derivative 3 were obtained as white solids (Scheme 2).

The chitosan conjugates $\mathbf{1}, \mathbf{2}$ and $\mathbf{3}$ are confirmed by their proton NMR spectra. The degree of substitution of cholic acid (DS) in compound 1, the degrees of substitution of cholic acid (DS) and galactosyl fragment (DSgal) in compound 2, the degrees of substitution of cholic acid (DS) and lactosyl fragment (DSlac) in compound $\mathbf{3}$ were obtained based on their elemental analysis. Further, these conjugates were analyzed for their size distribution and zeta potentials of their aqueous solutions. The morphologies of the above conjugates were observed using scanning electron microscopy.

The proton NMR spectra of chitosan, cholic acid conjugated chitosan derivative 1, cholic acid and galactose conjugated chitosan derivative 2, cholic acid and lactose conjugated chitosan derivative 3 were recorded in $\mathrm{D}_{2} \mathrm{O}(1 \mathrm{mg} / 1 \mathrm{~mL})$. By comparison of the spectra of conjugates 1, 2 and 3 with that of chitosan, the peaks from $0.6 \mathrm{ppm}$ to $1.7 \mathrm{ppm}$ in the spectra of compounds $\mathbf{1}, \mathbf{2}$ and $\mathbf{3}$ indicated the cholic acid fragments were linked to chitosan. Although the proton signals in the proton NMR of the conjugates 1, 2 and 3 confirmed the presence of cholic acid moiety, the degree of substitution of the cholic acid, galactose and lactose moieties could not be accurately calculated by comparing the ratio 
of the cholic acid proton to sugar protons due to the self-aggregation of conjugates in the aqueous phase.

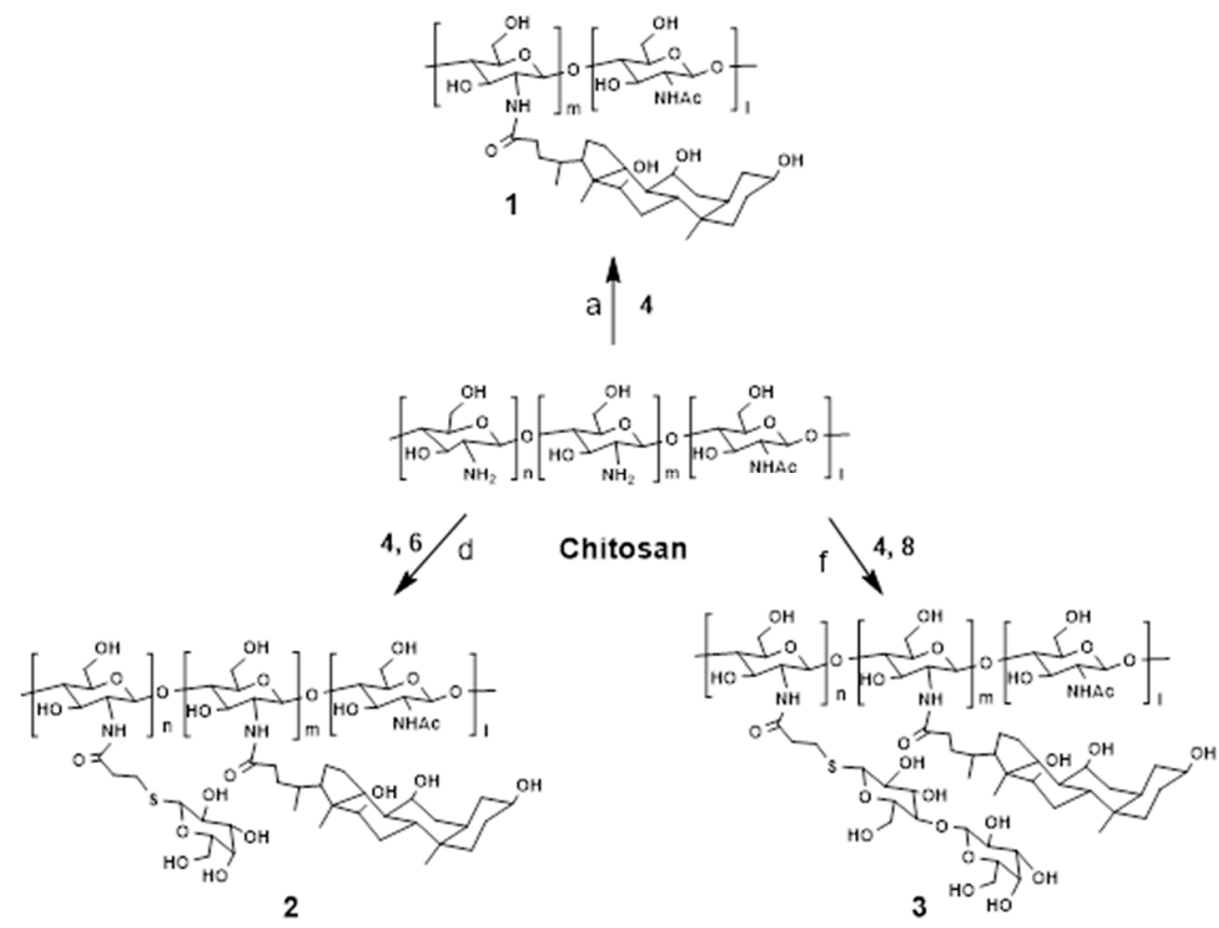

Scheme 2. Reagents and conditions. (a): chitosan (100 mg), 4 (from $200 \mathrm{mg}$ of cholic acid), dry DMSO $(5 \mathrm{~mL})$, room temperature, under nitrogen, $48 \mathrm{~h}$; (b): chitosan (100 mg), 4 (from $200 \mathrm{mg}$ of cholic acid), 6 (from $150 \mathrm{mg}$ of compound 5), dry DMSO (5 mL), room temperature, under nitrogen, $48 \mathrm{~h}$; (c): chitosan (100 mg), 4 (from $200 \mathrm{mg}$ of cholic acid), 8 (from $300 \mathrm{mg}$ of compound 7), dry DMSO $(5 \mathrm{~mL})$, room temperature, under nitrogen, $48 \mathrm{~h}$.

The substitution degree of cholic acid in conjugate $\mathbf{1}$, the substitution degrees of galactose and cholic acid in conjugate 2, and the substitution degrees of lactose and cholic acid in conjugate 3 were calculated according to their sulfur and the nitrogen contents, which were determined by elemental analysis (Table 1). For conjugate 1, from the ratio of $\mathrm{C}$ and $\mathrm{N}$ contents, the percentage of cholic acid substitution was determined to be $5.72 \%$; while for conjugate 2 , from the ratio of $\mathrm{S}$ and $\mathrm{N}$ contents, the percentage of galactosyl substitution degree was found to be $26.38 \%$, in addition, the ratio of $\mathrm{C}$ and $\mathrm{N}$ contents indicated the cholic acid substitution percentage as $6.68 \%$; and finally for conjugate 3 , from the ratio of $\mathrm{S}$ and $\mathrm{N}$ contents, the percentage of lactosyl substitution degree was found to be $11.65 \%$, and further from the ratio of $\mathrm{C}$ and $\mathrm{N}$ contents, the cholic acid percentage substitution was found to be $3.97 \%$ for this conjugate. The pattern of the degree of substitution in both mono-conjugate and the dual conjugates is in the expected range of the literature values to the close analogs of cholic acid, galactose and lactose. For example, the degree of substitution in cholic acid mono-conjugate $\mathbf{1}$ is in line with the reported values in the literature to its close analog [32]. Meanwhile, the substitution degrees of dual-conjugates ( 2 and 3 ) correspond to less than the mono-conjugates of carbohydrate derivatives of chitosans reported in the literature [33]. As expected, this may be due to competition and steric hindrance between the substitution groups in the dual-conjugates. The degree of substitution of galactosyl fragment in the dual-conjugate $\mathbf{2}$ is higher than that of the lactosyl fragment in dual-conjugate 3 . This may be expected, as the smaller size monosaccharide galactosyl group in compound $\mathbf{2}$ may have less steric hindrance than the larger lactosyl group in compound 3. 
Table 1. Degrees of substitution of cholic acid, galactosyl fragment and lactosyl fragment in chitosan conjugates.

\begin{tabular}{ccccccc}
\hline Samples & \multicolumn{2}{c}{ Elemental Analysis (\%) } & \multicolumn{2}{c}{ Degree of Substitutions (\%) } \\
\hline & $\mathbf{C}$ & $\mathbf{N}$ & $\mathbf{S}$ & Cholic Acid & Galactosyl Moiety & Lactosyl Moiety \\
\hline $\mathbf{1}$ & 39.15 & 6.03 & & 5.72 & & \\
\hline $\mathbf{2}$ & 38.05 & 5.67 & 3.42 & 6.68 & 26.38 & 11.65 \\
\hline $\mathbf{3}$ & 38.29 & 6.23 & 1.66 & 3.97 & & \\
\hline
\end{tabular}

The size distributions (Table 2) of nanoparticles of compounds 1, 2 and $\mathbf{3}$ were determined by dynamic light scattering and the results complement elemental analysis data. Accordingly, the size distribution of mono-conjugate $\mathbf{1}$ is in agreement with cholic acidrelated conjugate reported in the literature [32]. As expected, the sizes (nM) of NPs of dual-conjugates $\mathbf{2}$ and $\mathbf{3}$ are higher than that of mono-conjugate $\mathbf{1}$ (see Figures 2-4). The zeta potentials of self-aggregated nanoparticles of chitosan conjugates 1, 2, and 3 were listed in Table 2. The zeta potential of dual conjugates $\mathbf{2}$ and $\mathbf{3}$ (Figures 3 and 4) are higher than that of monoconjugate 1 (Figure 2), and this corresponds to the size distribution of conjugates. The observed zeta potentials pattern is counter-intuitive, as due to the higher degree of substitution in chitosan-conjugates, it is expected that the derivatives will show less surface charge due to less availability of charged species. However, the observed zeta potentials pattern may be reasoned, due to the pattern of formation of nanoparticles and their surface area. The larger surface area of the dual-conjugates may contribute to their larger zeta potentials in comparison to that of the monoconjugate.

Table 2. Size distribution and Zeta potential of the self-aggregated nanoparticles of chitosan conjugates.

\begin{tabular}{cccc}
\hline Samples & $\begin{array}{c}\text { Critical Aggregation } \\
\text { Concentration }\end{array}$ & Diameter (nm) & Zeta Potential (mV) \\
\hline $\mathbf{1}$ & $1 \mathrm{mg} / \mathrm{mL}$ & 219.1 & 14.1 \\
\hline $\mathbf{2}$ & $1 \mathrm{mg} / \mathrm{mL}$ & 571.5 & 38.3 \\
\hline $\mathbf{3}$ & $1 \mathrm{mg} / \mathrm{mL}$ & 474.7 & 34.8 \\
\hline
\end{tabular}
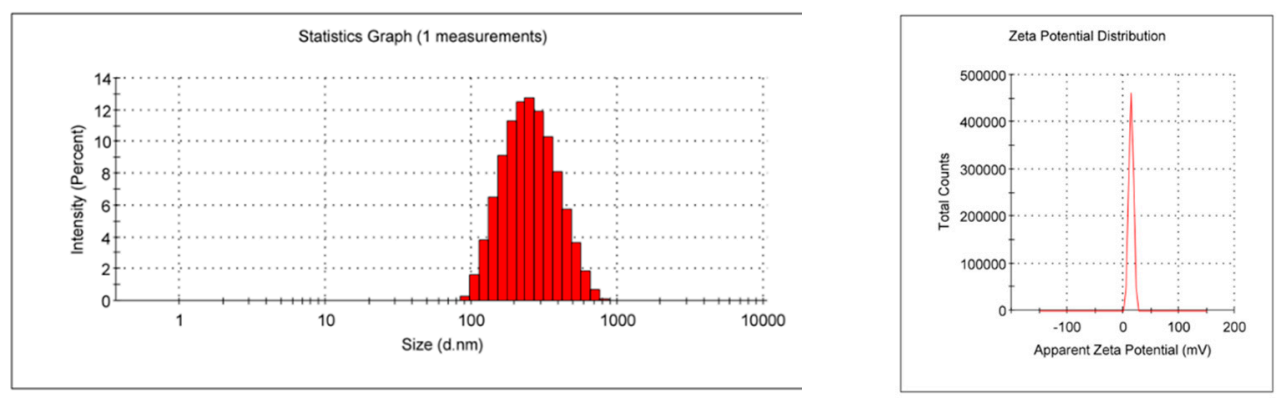

Figure 2. Size distribution and Zeta potential of chitosan Conjugate 1.

Morphologies of self-aggregated nanoparticles of chitosan conjugates 1, 2 and 3 were observed by scanning electron microscope, and the SEM photographs of chitosan conjugates 1, 2 and $\mathbf{3}$ were shown in Figures 5-7. The monoconjugate nanoparticles shape appears to be distinctly different from that of dual-conjugates. 

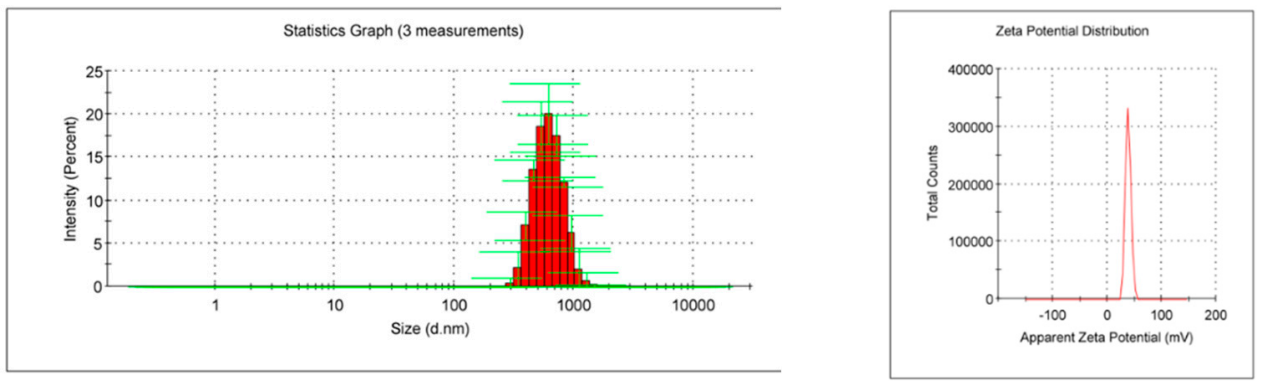

Figure 3. Size distribution and Zeta potential of chitosan Conjugate 2.
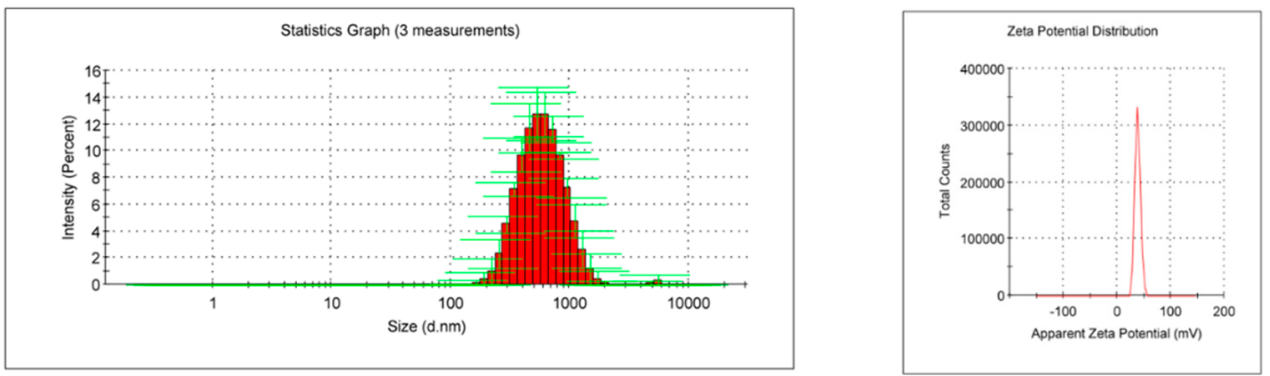

Figure 4. Size distribution and Zeta potential of chitosan Conjugate 3.

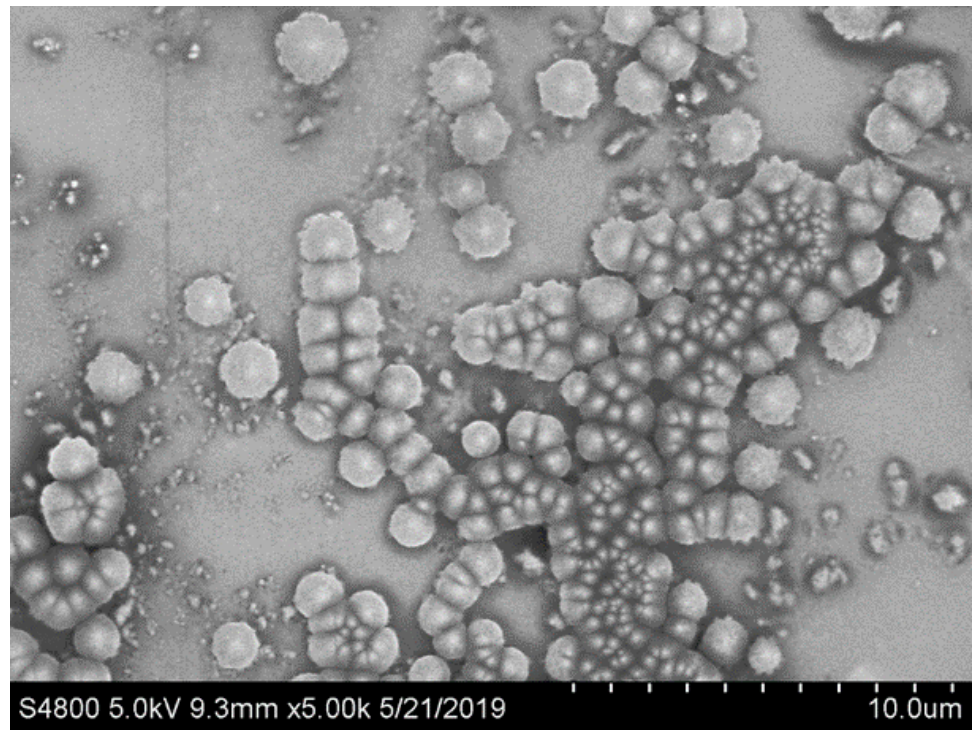

Figure 5. SEM image of cholic conjugated chitosan derivative $\mathbf{1}$. 


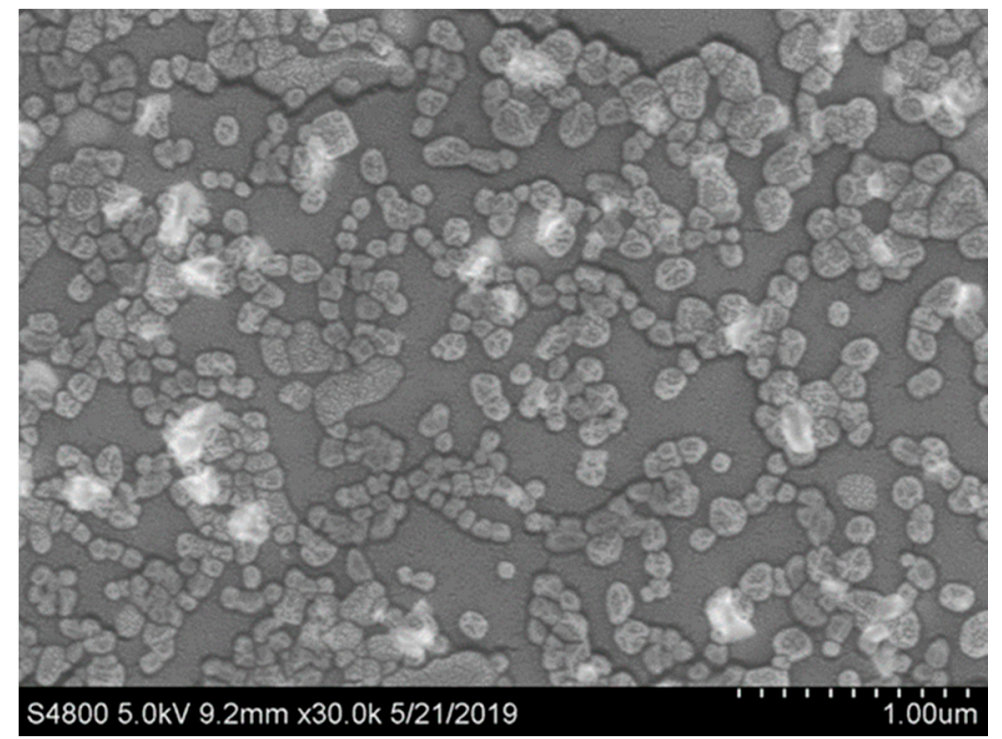

Figure 6. SEM image of cholic conjugated chitosan derivative 2.

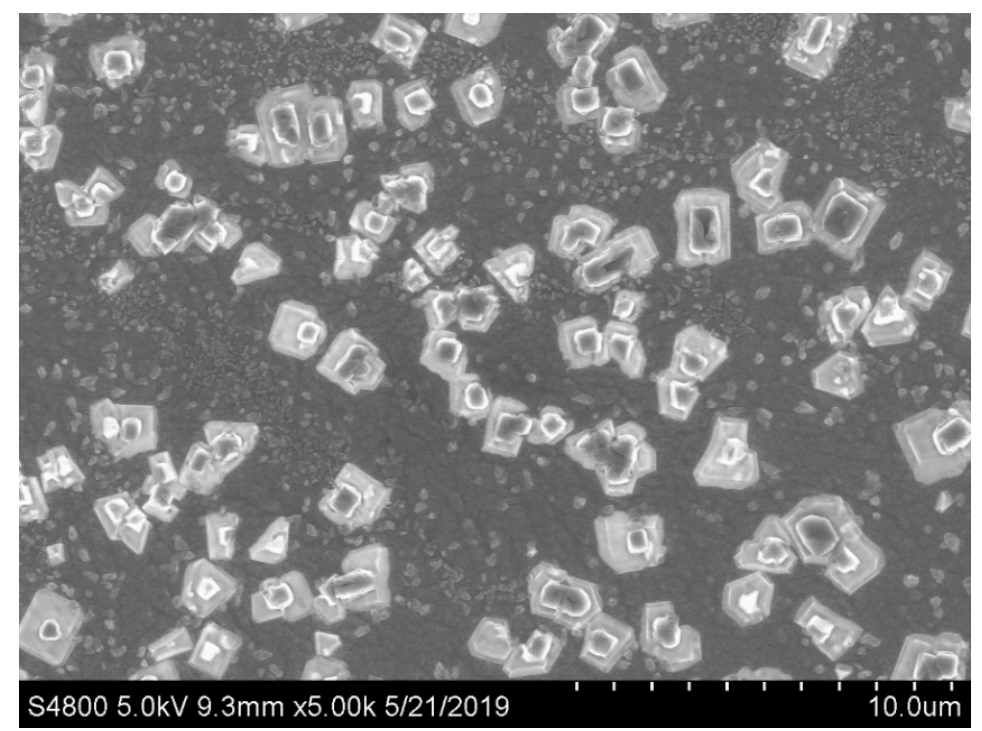

Figure 7. SEM image of cholic conjugated chitosan derivative 3.

The proton nmr spectra of the conjugates 1, 2, and 3 were recorded and shown in Figures 8-10. By comparison with the proton nmr spectrum of chitosan (Figure 11), it was confirmed that these three conjugates contain the cholic fragments, as there are peaks from $2.0 \mathrm{ppm}$ to $0.8 \mathrm{ppm}$ in their nmr spectra. 


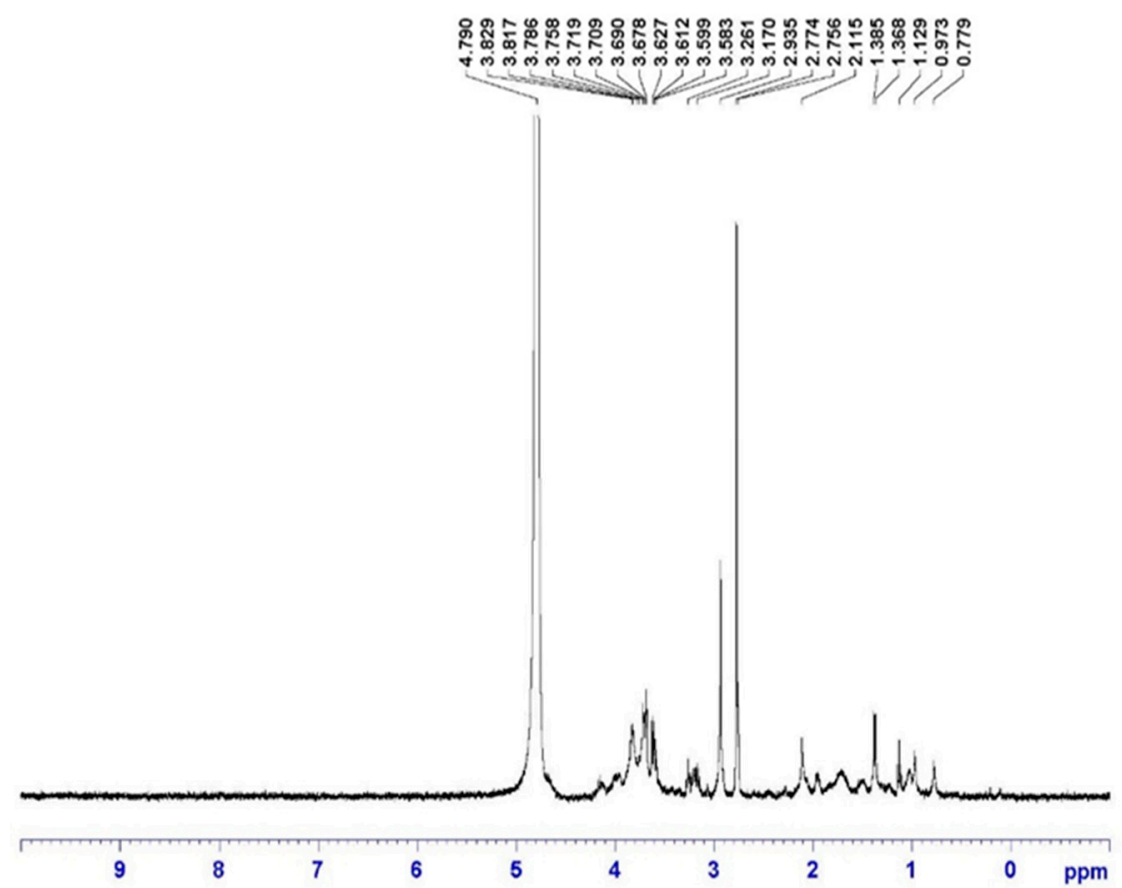

Figure 8. Proton NMR spectrum of cholic acid conjugated chitosan derivative 1 in $\mathrm{D}_{2} \mathrm{O}$.

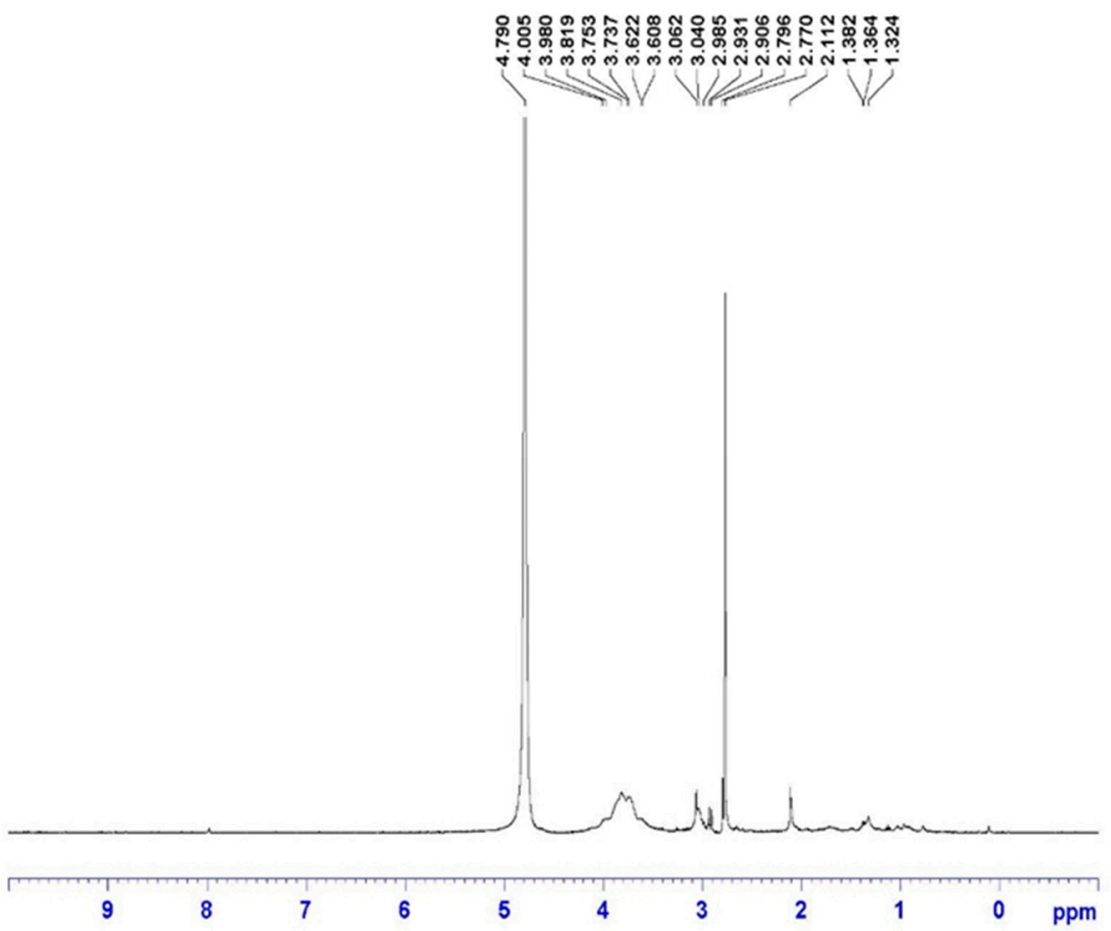

Figure 9. Proton NMR spectrum of galactose and cholic acid conjugated derivative 2 in $\mathrm{D}_{2} \mathrm{O}$. 


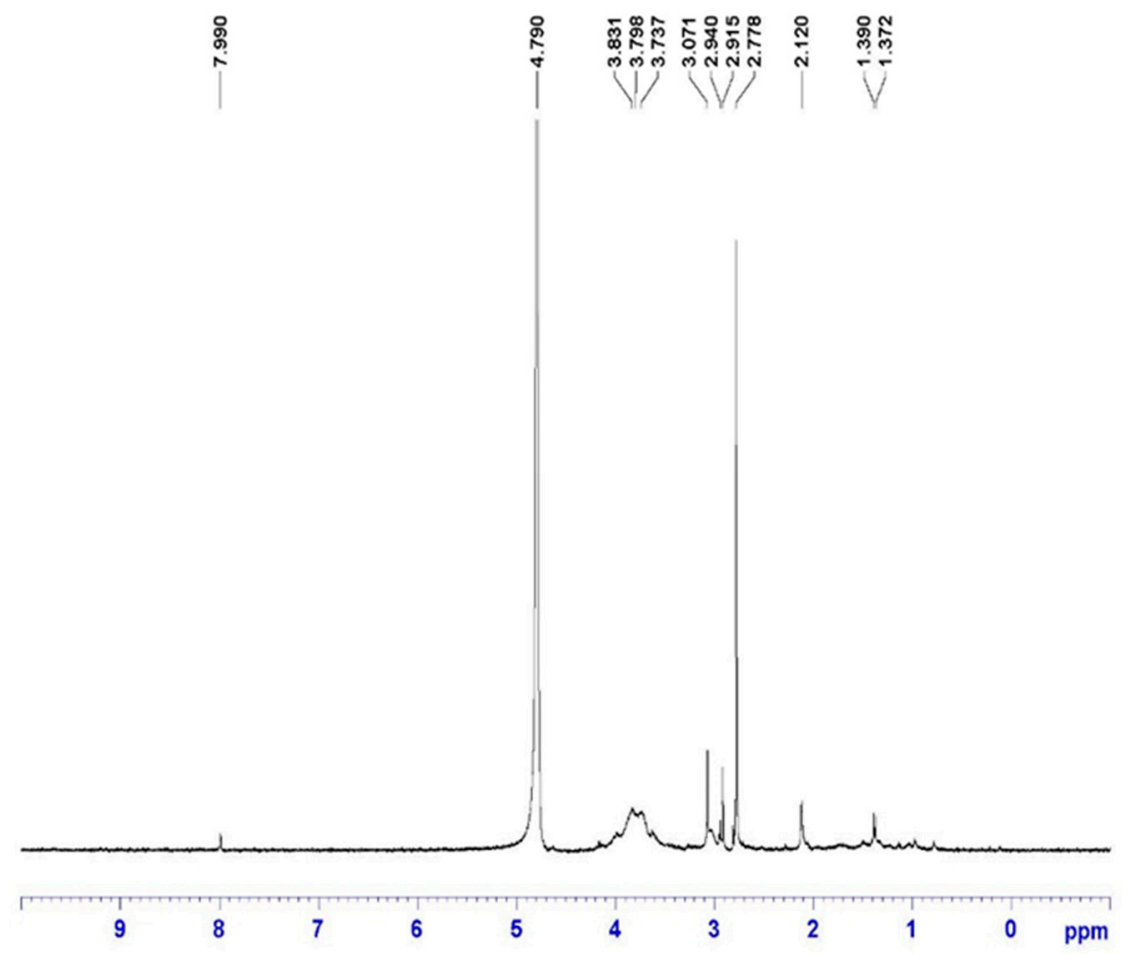

Figure 10. Proton NMR spectrum of lactose and cholic acid conjugated chitosan derivative 3 in $\mathrm{D}_{2} \mathrm{O}$.

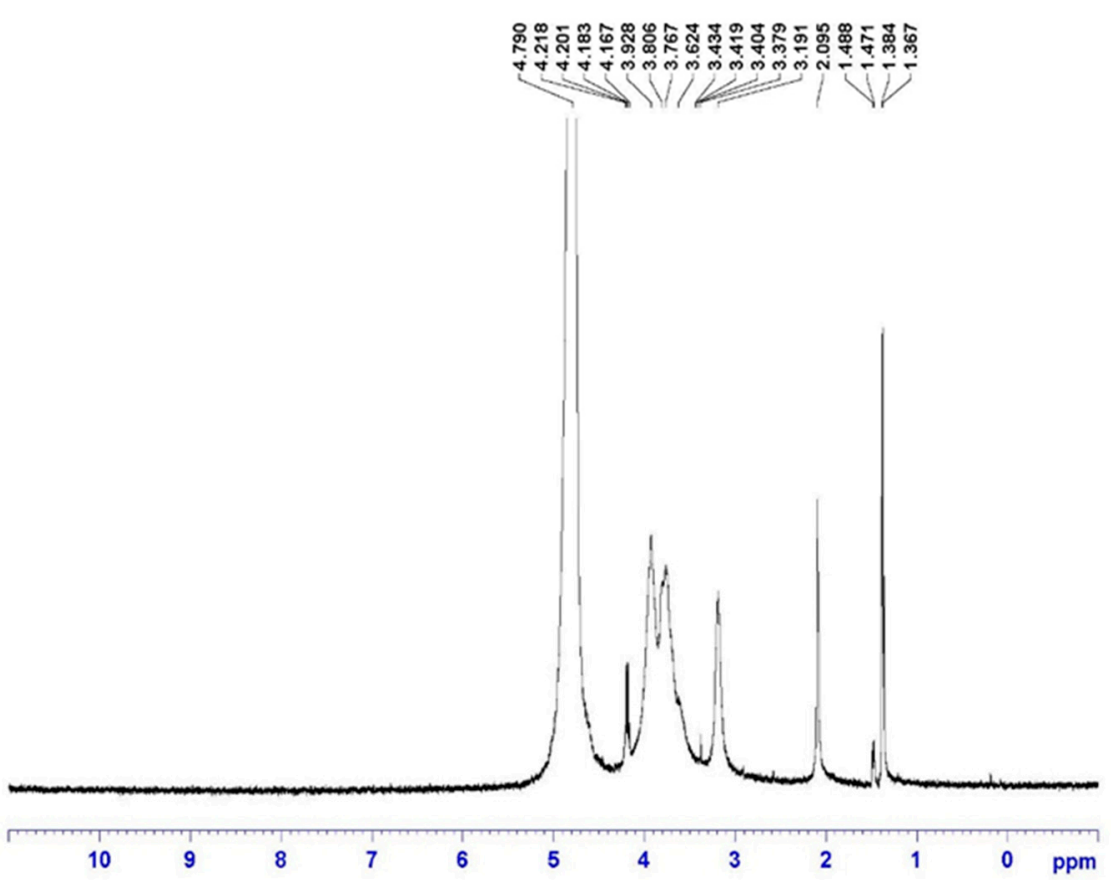

Figure 11. Proton NMR spectrum of chitosan in $\mathrm{D}_{2} \mathrm{O}$.

Chitosan conjugates 1, 2, and $\mathbf{3}$ as the dual liver cell targeting nano-drug carriers may increase sorafenib's water solubility. The sorafenib inclusion compounds $1 \mathrm{~S}, \mathbf{2 S}$, and $3 \mathrm{~S}$ were obtained as white solids.

The entrapment efficiency (EE\%) and drug content (DC\%) of sorafenib in the inclusion complexes 1S, $2 \mathrm{~S}$ and $\mathbf{3 S}$ were measured based on the absorption of UV light in an ultraviolet spectrophotometer against the standard curve obtained.

Thus, for the sorafenib inclusion complex 1S, the amount of sorafenib was found to be $1.6 \mathrm{mg}$. Accordingly, the calculated values of DC\% (weight of the drug in micelles/weight 
of feeding polymer and drug) and the EE\% (weight of the drug in micelles/weight of the feeding drug) were found to be $32 \%$ and $67 \%$, respectively. For the sorafenib inclusion complex 2S, the amount of sorafenib was calculated to be $1.9 \mathrm{mg}$. The DC and EE values for this complex were found to be $38 \%$ and $93 \%$, respectively. Lastly, for the sorafenib inclusion complex $3 \mathrm{~S}$, the amount of sorafenib was found to be $1.7 \mathrm{mg}$. The DC\% and the $\mathrm{EE} \%$ values for complex $3 \mathrm{~S}$ were found to be $34 \%$ and $80 \%$, respectively.

As we hypothesized, the sorafenib chitosan conjugate inclusion compounds 1S, 2S, and $3 \mathrm{~S}$ were found to have increased the solubility of the drug. Most importantly, inclusion complex $2 \mathrm{~S}$ demonstrated about an 1117-fold increase in the solubility of sorafenib in comparison to its solubility without the aid of chitosan conjugate.

\section{Conclusions}

In this preliminary study, we reported the design and synthesis of the chitosan conjugate of cholic acid, the dual conjugate of cholic acid and galactose, and dual conjugate of cholic acid and lactose, and evaluated their ability to improve the aqueous solubility of cancer drug sorafenib. The evaluated conjugates demonstrated their ability to enhance the aqueous solubility of sorafenib in comparison to that of sorafenib alone. Among the conjugates studied, dual chitosan conjugate with cholic acid and galactose (2) was found to be best in enhancing the aqueous solubility of sorafenib. Further, evaluation of dual conjugate $\mathbf{2}$ for improving the solubility of additional drugs and their biological studies is in progress, and will be reported in due course.

Author Contributions: Conceptualization, Y.D. and C.V.N.S.V.P.; writing-original draft preparation, Y.D.; writing—review and editing, Y.D. and C.V.N.S.V.P.; formal analysis, funding acquisition, Y.D.; supervision, Y.D.; project administration, Y.D; and investigation: Y.D., W.C. and B.W. All authors have read and agreed to the published version of the manuscript.

Funding: The research project was funded by the "Innovation and Entrepreneurship Team Project" of the Blue Ocean Talents Program in Shishan Town, Nanhai District, Foshan City, Guangdong Province, for a period of three years (2019-2021, the ninth batch, funding number: 201804300016).

Institutional Review Board Statement: Not applicable.

Informed Consent Statement: Not applicable.

Data Availability Statement: Not applicable.

Conflicts of Interest: The authors declare no conflict of interest.

\section{References}

1. Bahrami, B.; Hojjat-Farsangi, M.; Mohammadi, H.; Anvari, E.; Ghalamfarsa, G.; Yousefi, M.; Jadidi-Niaragh, F. Nanoparticles and targeted drug delivery in cancer therapy. Immunol. Lett. 2017, 190, 64-83. [CrossRef]

2. Cho, K.; Wang, X.; Nie, S.; Chen, Z.; Shin, D.M. Therapeutic nanoparticles for drug delivery in cancer. Clin. Cancer Res. 2008, 14, 1310-1316. [CrossRef]

3. Massoudinejada, M.; Rasoulzadehb, H.; Ghaderpooric, M. Magnetic chitosan nanocomposite: Fabrication, properties, and optimization for adsorptive removal of crystal violet from aqueous solutions. Carbohydr. Polym. 2019, 206, 844-853. [CrossRef] [PubMed]

4. Kumar, M.N.; Muzzarelli, R.A.; Muzzarelli, C.; Sashiwa, H.; Domb, A.J. Chitosan chemistry and pharmaceutical perspectives. Chem. Rev. 2004, 104, 6017-6084. [CrossRef]

5. Illum, L. Chitosan and its use as a pharmaceutical excipient. Pharm. Res. 1998, 15, 1326-1331. [CrossRef]

6. Felt, O.; Buri, P.; Gurny, R. Chitosan: A unique polysaccharide for drug delivery. Drug Dev. Ind. Pharm. 1998, $24,979-993$. [CrossRef] [PubMed]

7. Patel, M.P.; Patel, R.R.; Patel, J.K. Chitosan mediated targeted drug delivery system: A review. J. Pharm. Pharm. Sci. 2010, 13, 536-557. [CrossRef]

8. Virtanen, E.; Kolehmainen, E. Use of bile acids in pharmacological and supramolecular applications. Eur. J. Org. Chem. 2004, 16, 3385-3399. [CrossRef]

9. Zhang, Z.; Li, H.; Xu, G.; Yao, P. Liver-targeted delivery of insulin-loaded nanoparticles via enterohepatic circulation of bile acids. Drug Deliv. 2018, 25, 1224-1233. [CrossRef] 
10. Chae, S.Y.; Son, S.; Lee, M.; Jang, M.K.; Nah, J.W. Deoxycholic acid-conjugated chitosan oligosaccharide nanoparticles for efficient gene carrier. J. Control Release 2005, 109, 330-344. [CrossRef]

11. Ho, N.F.H. Utilizing bile acid carrier mechanisms to enhance liver and small intestine absorption. Ann. N. Y. Acad. Sci. 1987, 507, 315-329. [CrossRef]

12. Dawson, P.A. Role of the intestinal bile acid transporters in bile acid and drug disposition. Handb. Exp. Pharmacol. 2011, 201, 169-203.

13. Pasanphan, W.; Buettner, G.R.; Chirachanchai, S. Chitosan conjugated with deoxycholic acid and gallic acid: A novel biopolymerbased additive antioxidant for polyethylene. J. Appl. Poly. Sci. 2008, 109, 38-46. [CrossRef]

14. Kim, K.; Kwon, S.; Park, J.H.; Chung, H.; Jeong, S.Y.; Kwon, I.C.; Kim, I.S. Physicochemical characterizations of self-assembled nanoparticles of glycol chitosan-deoxycholic acid conjugates. Biomacromolecules 2005, 6, 1154-1158. [CrossRef]

15. Zhang, Z.; Cai, H.; Liu, Z.; Yao, P. Effective enhancement of hypoglycemic effect of insulin by liver-targeted nanoparticles containing cholic acid-modified chitosan derivative. Mol. Pharm. 2016, 13, 2433-2442. [CrossRef]

16. Park, J.-K.; Kim, T.-H.; Nam, J.-P.; Park, S.C.; Park, Y.H.; Jang, M.-K.; Nah, J.-W. Bile acid conjugated chitosan oligosaccharide nanoparticles for paclitaxel carrier. Macromol. Res. 2014, 22, 310-317. [CrossRef]

17. Roos, P.H.; Kolb-Bachofen, V.; Schlepper-Schäfer, J.; Monsigny, M.; Stockert, R.J.; Kolb, H. Two galactose-specific receptors in the liver with different function. FEBS Lett. 1983, 157, 253-256. [CrossRef]

18. Roggenbuck, D.; Mytilinaiou, M.G.; Lapin, S.V.; Reinhold, D.; Conrad, K. Asialoglycoprotein receptor (ASGPR): A peculiar target of liver-specific autoimmunity. Autoimmun. Highlights 2012, 3, 119-125. [CrossRef]

19. Yang, K.W.; Li, X.R.; Yang, Z.L.; Li, P.Z.; Wang, F.; Liu, Y. Novel polyion complex micelles for liver-targeted delivery of diammonium glycyrrhizinate: In vitro and in vivo characterization. J. Biomed. Mater. Res. 2009, 88A, 140-148. [CrossRef]

20. Zhang, C.; Ping, Q.; Ding, Y. Synthesis and characterization of chitosan derivatives carrying galactose residues. J. Appl. Polym. Sci. 2005, 97, 2161-2167. [CrossRef]

21. Zhao, R.; Li, T.; Zheng, G.; Jiang, K.; Fan, L.; Shao, J. Simultaneous inhibition of growth and metastasis of hepatocellular carcinoma by co-delivery of ursolic acid and sorafenib using lactobionic acid modified and $\mathrm{pH}$-sensitive chitosan-conjugated mesoporous silica nanocomplex. Biomaterials 2017, 143, 1-16. [CrossRef]

22. Li, L.; Liang, N.; Wang, D.; Yan, P.; Kawashima, Y.; Cui, F. Amphiphilic polymeric micelles based on deoxycholic acid and folic acid modified chitosan for the delivery of paclitaxel. Int. J. Mol. Sci. 2018, 19, 3132. [CrossRef]

23. Ding, Y.; Vara Prasad, C.V.N.S.; Ding, C.; Wang, B. Synthesis of carbohydrate conjugated 6A,6D-bifunctionalized $\beta$ cyclodextrin derivatives as potential liver cancer drug carriers. Carbohydr. Polym. 2018, 181, 957-963. [CrossRef] [PubMed]

24. Gotink, K.J.; Verheul, H.M.W. Anti-angiogenic tyrosine kinase inhibitors: What is their mechanism of action? Angiogenesis 2010, 13, 1-14. [CrossRef]

25. Liu, C.Y.; Chen, Z.; Chen, Y.J.; Lu, J.; Li, Y.; Wang, S.J.; Wu, G.L.; Qian, F. Improving oral bioavailability of Sorafenib by optimizing the "spring" and "parachute" based on molecular interaction mechanisms. Mol. Pharm. 2016, 13, 2599-2608. [CrossRef]

26. Kim, D.W.; Talati, C.; Kim, R. Hepatocellular carcinoma (HCC): Beyond sorafenib-Chemotherapy. J. Gastrointest. Oncol. 2017, 8, 256-265. [CrossRef] [PubMed]

27. Khan, M.A.; Raza, A.; Ovais, M.; Sohail, M.F.; Ali, S. Current state and prospects of nano-delivery systems for sorafenib. Int. J. Polym. Mater. Polym. Biomater. 2018, 67, 1105-1115. [CrossRef]

28. Cho, E.; Jung, S. Supramolecular complexation of carbohydrates for the bioavailability enhancement of poorly soluble drugs. Molecules 2015, 20, 19620-19646. [CrossRef]

29. Kong, F.H.; Ye, Q.F.; Miao, X.Y.; Liu, X.; Huang, S.Q.; Xiong, L.; Wen, Y.; Zhang, Z.J. Current status of sorafenib nanoparticle delivery systems in the treatment of hepatocellular carcinoma. Theranostics 2021, 11, 5464-5490. [CrossRef]

30. Nelson, A.; Stoddart, J.F. Dynamic multivalent lactosides displayed on cyclodextrin beads dangling from polymer strings. Org. Lett. 2003, 5, 3783-3786. [CrossRef]

31. Ashton, P.R.; Boyd, S.E.; Brown, C.L.; Nepogodiev, S.A.; Meijer, E.W.; Peerlings, H.W.I.; Stoddart, J.F. Synthesis of glycodendrimers by modification of poly (propylene imine) dendrimers. Chem. Eur. J. 1997, 3, 974-984. [CrossRef]

32. Park, J.H.; Cho, Y.W.; Chung, H.; Kwon, I.C.; Jeong, S.Y. Synthesis and Characterization of Sugar-Bearing Chitosan Derivatives: Aqueous Solubility and Biodegradability. Biomacromolecules 2003, 4, 1087-1091. [CrossRef] [PubMed]

33. Yang, T.; Chou, C.; Li, C. Preparation, water solubility and rheological property of the N-alkylated mono or disaccharide chitosan derivatives. Food Res. Int. 2002, 35, 707-713. [CrossRef] 